\title{
Nell-1, HMGB1 and CCN2 enhance migration and vasculogenesis, but not osteogenic differentiation compared to BMP2
}

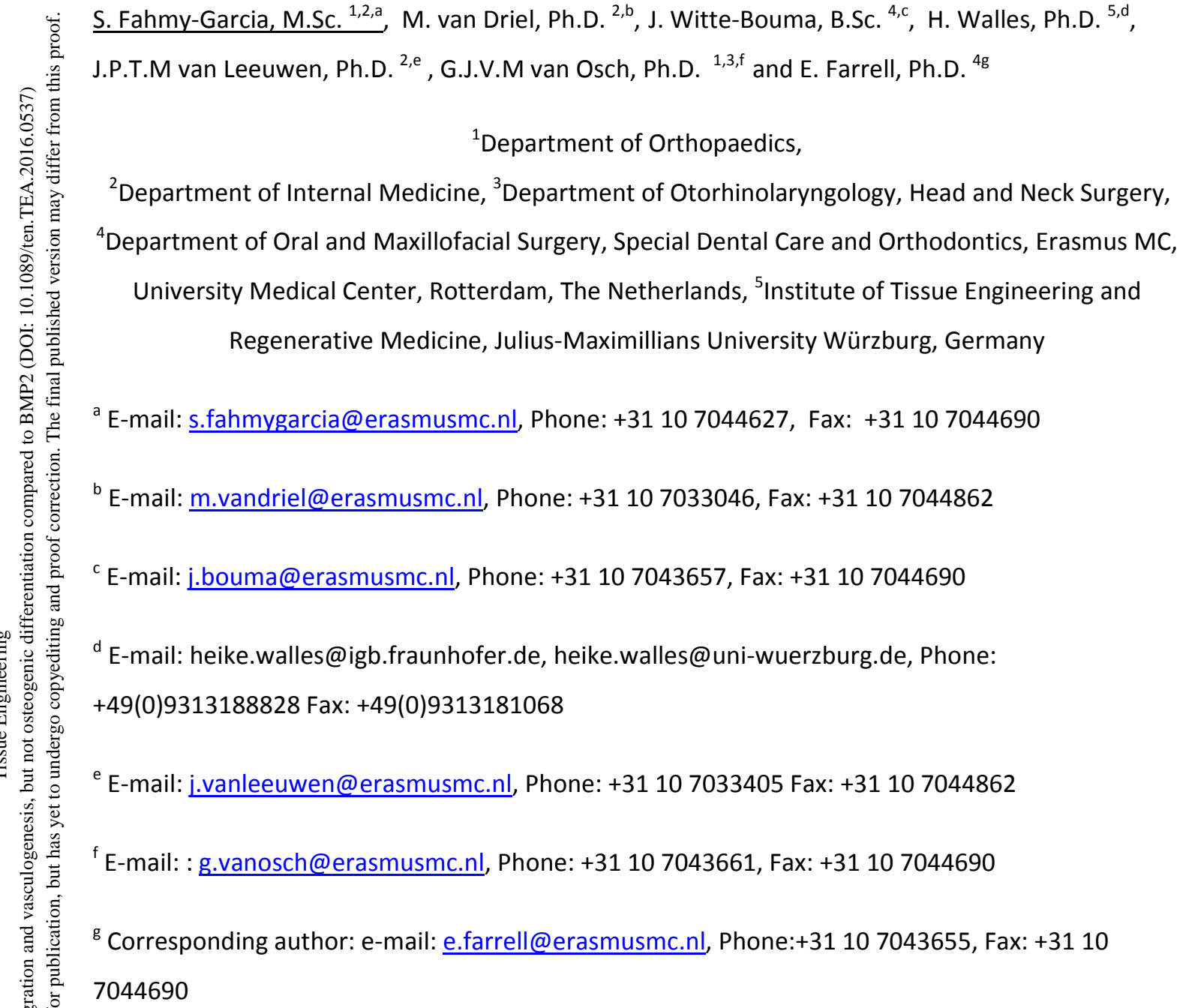

- The work was performed in the Department of Internal Medicine and the Department of Orthopaedics at the Erasmus MC, University Medical Center, Rotterdam. 


\section{Introduction}

Currently, bone grafting is used to replace missing bone and to repair bone fractures, with 2.2 million transplantations per year [1]. Autografts represent the golden standard due to their histocompatibility and capacity to become vascularized and fully integrated with the surrounding bone. Although autografts have an excellent success rate, the harvesting of autologous bone is associated with a $8.6 \%$ rate of major and 20.6\% minor complications [2]. Therefore, different approaches are being taken to overcome these limitations. The ideal regenerative medicine approach would involve an off the shelf product that can recruit a patient's own cells and stimulate them to differentiate into mature osteoblasts while at the same time inducing tissue vascularization. One such approach is growth factor-based therapy. This involves the use of molecules that are essential for tissue formation combined with biomaterials [3].

BMP2 and BMP7 are the most studied bone forming proteins. Moreover, currently BMP2 is the only bone morphogenetic protein approved as a bone graft substitute [4]. However, despite the therapeutic potential of BMP2 in bone repair, large doses (up to $40 \mathrm{mg}$ ) are needed to produce a significant osteogenic effect [5], and this can result in undesired ectopic bone formation, soft tissue swelling, bone resorption, and tumor growth enhancement through angiogenesis stimulation [6-8].

Accordingly, alternative proteins are being assessed for their osteogenic induction capacity. Three of such a proteins are nel-like molecule type 1 (Nell-1), connective tissue growth factor (also known as CCN2); and high mobility group box 1 (HMGB1). Bone regeneration is a complex process that involves a series of wellorchestrated biological events. At the cellular level, migration, proliferation, angiogenesis, osteogenic differentiation and subsequent mineralization are essential processes to enable bone formation and repair to occur [9]. To optimize in vivo bone defect repair using biologicals, more knowledge of the effect of these factors on the different processes is necessary.

Nell-1 is a secretory protein and its overexpression induces altered bone formation and it is considered an essential factor for human craniosynostosis [10]. It has been shown to promote bone formation on mice in vivo [11, 12], and in a comparison study Nell1-based bone grafts were comparable to BMP2-based grafts in rat spinal fusion [13]. Recent studies performed upon osteoporotic mice and sheep have shown that Nell-1 could potentially be used as a therapy for osteoporotic bone loss $[14,15]$. Furthermore, Nell-1 has been shown to increase osteogenic differentiation in vitro [16]. However, whether Nell-1 is able to recruit osteoprogenitor cells is not known yet. Moreover, several genes affected by Nell-1 appear to promote angiogenesis at early stages of bone regeneration [17] but whether it is able to promote endothelial cell (EC) recruitment and differentiation is still unknown.

CCN2 has been used mostly in rats and have been shown to promote bone and cartilage regeneration [18, 19]. It is one of the $6 \mathrm{CCN}$ matricellular proteins characterized by their conserved modular structure [20] and interacts with integrins, enhancing cellular processes such as adhesion, ECM synthesis, cytoskeleton reorganization and survival [21-23]. In vitro studies have shown that overexpressing cells with CCN2 promote 


$$
\text { 30]. }
$$

mesenchymal cell proliferation, migration and aggregation [24, 25]. Additionally, it has been shown that CCN2 expression was increased in mesenchymal stem cells and osteoblasts during formation of new bone, suggesting its role in bone development [20], but its effect when added to either human osteoprogenitor cells or osteoblasts has not been investigated yet. Furthermore, CCN2 is a necessary mediator for the production of vascular basement membranes [26], however, its effect on angiogenesis remains unclear [27-

HMGB1, unlike Nell-1 and CCN2, has never been used as growth factor-based therapy but knowledge about the potency of this factor in the different processes involved in bone repair makes it an attractive candidate. HMGB1 is a chromatin protein mainly known due to its role as an alarmin [31, 32]. Consequently, many studies showed that HMGB1 is a potent pro-inflammatory cytokine secreted by monocytes and macrophages able to regulate migration of mesongioblasts, smooth muscle cells or myoblasts among others [33-36]. Recently it has been shown that HMGB1 has an osteo-modulatory action [37], being chemotactic to MSCs [38] as well as osteoblasts and osteoclasts during endochondral ossification [31, 39]. Although HMGB1 is known to be able to upregulate osteogenic markers when added to MSC culture in vitro [40], its direct effect upon osteoprogenitor and pre-osteoblasts mineralization has not been studied. In addition, various studies have identified it as a putative proangiogenic factor and its overexpression is related with an increased ability to develop blood vessels $[34,41,42]$.

Nell-1, HMGB1 and CCN2 are indicated to play a role in bone formation. However, their effect upon major cell types and specific processes involved in bone formation is barely studied, and they were never directly compared. The main goal of this study is to compare side by side Nell-1, HMGB1 and CCN2 to BMP2 and assess whether they are able to induce cell migration, osteogenic differentiation and neovascularization, indispensable processes needed for bone formation. This was performed using cells from human origin: two types of osteoprogenitors (human mesenchymal stem cells (MSCs) and fetal osteoblasts) and human umbilical vein endothelial cells (HUVECs).

\section{Materials and methods}

\section{Cell culture}

Human MSCs were obtained from leftover material from iliac crest biopsies of four donors (age 9-12 years; three males and one female) undergoing cleft palate reconstruction surgery (Erasmus MC ethical committee number MEC-2014-106) with implicit consent. Cells were seeded at a density of 50,000 cells $/ \mathrm{cm}^{2}$ in $\alpha$-MEM (Gibco, BRL, Paisley, UK), supplemented with 10\% FCS, $1 \mathrm{ng} / \mathrm{mL}$ FGF2, $25 \mu \mathrm{g} / \mathrm{mL}$ ascorbic acid-2-phosphate, $1.5 \mu \mathrm{g} / \mathrm{mL}$ fungizone and $50 \mu \mathrm{g} / \mathrm{mL}$ gentamicin. After $24 \mathrm{~h}$, non-adherent cells were washed out and adherent cells were expanded in the above-mentioned medium. The medium was renewed twice per week until MSCs neared confluency. Then, cells were used for migration or osteogenic differentiation assays. 
Simian Virus-immortalized Human Fetal Osteoblast (SV-HFO) cells [43] were expanded and cultured as previously described [44].

HUVECs (Lonza, Walkersville, MD, USA) were cultured at a density of 5,000 cells $/ \mathrm{cm}^{2}$ in endothelial growth medium (EGM-2 with SingleQuots (Lonza)). Medium was renewed every 2-3 days. When cells neared confluency they were used for migration or tube formation assays.

\section{Migration assay}

MSC and HUVEC migration was assessed using modified Boyden chambers (polyethylene terephtalate cell culture inserts, pore size: $8 \mu \mathrm{m}$ in diameter, Millipore-Merck, NL). Briefly, to analyze MSC migration, $\alpha-M E M$ containing Nell-1 (0.07-3.5 nM (10-500 ng/ml), R\&D systems, Abingdon, UK), CCN2 (0.89-8.9 nM (10-100 $\mathrm{ng} / \mathrm{mL})$, Abnova, Taipei, Taiwan), HMGB1 (0.4-4 nM (10-100ng/mL), R\&D systems, Minneapolis, CA, USA) and BMP2 (0.38-38 nM (10-1000 ng/ml), kindly provided by Dr. Joachim Nickel, Fraunhofer IGB, Germany) was added to the lower chamber of a 24-well plate. PDGF-AB $(20 \mathrm{ng} / \mathrm{ml})$ or $10 \%$ FCS were used as positive controls. $6 \times 10^{3}$ MSCs suspended in a volume of $200 \mu \mathrm{l} \alpha$-MEM were added into the upper chamber. The plates were incubated at $37^{\circ} \mathrm{C}$ for $17 \mathrm{~h}$. To test the chemotactic effect of Nell-1 (10-500 ng/ml), CCN2 (10-100 $\mathrm{ng} / \mathrm{ml})$, HMGB1 (10-100 ng/ml) and BMP2 (10-1000 ng/ml) upon HUVECs, endothelial cell basal medium (EBM-2, Lonza) containing either Nell-1, CCN2, HMGB1 or BMP2 was added in the lower chamber. EGM-2 medium was used as positive control. $5 \times 10^{4}$ HUVECs were added into the upper chamber. The plates, were incubated at $37^{\circ} \mathrm{C}$ for $10 \mathrm{~h}$. In both cases, the membrane was then washed and the cells remaining on the upper surface of the chambers were mechanically removed with a cotton swab. Those which had migrated to the lower surface were fixed with $4 \%$ formalin, stained with 4',6-diamidino-2-phenylindole (DAPI) (100 $\mathrm{ng} / \mathrm{mL}$ ) in the dark for $5 \mathrm{~min}$ and imaged using fluorescence microscopy (Zeiss Axiovert 200M Fluorescence Imaging, Sliedrecht, NL) in five random fields for each membrane and counted using ImageJ software.

\section{Osteogenic differentiation}

Osteogenic differentiation assays were performed on MSCs and SV-HFOs. 3000 Cells $/ \mathrm{cm}^{2}$ (MSCs) or 9000 cells $/ \mathrm{cm}^{2}$ (SV-HFOs) were seeded with $\alpha$-MEM in a 12-well plate. For MSCs, after $24 \mathrm{~h}$ the medium was replaced with complete osteogenic medium; DMEM High Glucose (Gibco) with 10\% FCS, $1.5 \mu \mathrm{g} / \mathrm{mL}$ fungizone, $50 \mu \mathrm{g} / \mathrm{mL}$ gentamicin, $1 \mathrm{ng} / \mathrm{mL} \mathrm{FGF}-2,25 \mu \mathrm{g} / \mathrm{mL}$ ascorbic acid-2-phosphate, $10 \mathrm{mM} \beta$ glycerophosphate and $0.1 \mu \mathrm{M}$ dexamethasone. For SV-HFOs, the osteogenic differentiation medium consisted of phenol-red free $\alpha$-MEM (Gibco), pH 7.5, supplemented with $20 \mathrm{mM}$ HEPES (Sigma), streptavidin/penicillin, $1.8 \mathrm{mM} \mathrm{CaCl} 2 \cdot 2 \mathrm{H} 2 \mathrm{O}$ (Sigma), 2\% heat-inactivated charcoal-treated FCS, $0.1 \mu \mathrm{M}$ dexamethasone and $10 \mathrm{mM} \beta$-glycerophosphate. During each medium refreshment medium was supplemented with proteins of interest; Nell-1 (10 -500 ng/ml), CCN2 (10-100 ng/mL), HMGB1 (10-100 $\mathrm{ng} / \mathrm{mL}$ ) and BMP2 (10-1000 ng/ml). Osteogenic differentiation was carried out until onset of mineralization, monitored by measuring calcium concentration in the culture supernatant. Cells were scraped from the culture dish in PBS/ 0.1\% Triton X-100. Cell lysates were sonicated on ice before analysis. 


\section{DNA and protein measurements}

For DNA measurement cell lysates were incubated 30 minutes at $37^{\circ} \mathrm{C}$ with $100 \mu \mathrm{L}$ heparin $(8 \mathrm{IU} / \mathrm{mL}$ in PBS) and $50 \mu \mathrm{L}$ RNAse A (50 $\mu \mathrm{g} / \mathrm{ml}$ in PBS) solution. Ethidium bromide solution $(25 \mu \mathrm{g} / \mathrm{mL})$ was added and DNA content was measured on the Wallac 1420 Victor2 (PerkinElmer Life and Analytical Science, Waltham, MA) plate reader using and excitation filter of $340 \mathrm{~nm}$ and emission filter of $590 \mathrm{~nm}$. For standards, calf thymus DNA (Sigma) was used.

Protein was measured in cell lysates with BCA protein assay (Pierce ${ }^{\mathrm{TM}}$ BCA Protein assay, Thermo Scientific, Rockford, IL) according to manufacturer's instructions.

\section{Alkaline phosphatase (ALP) activity}

ALP activity was performed as described previously [45] by determining the release of paranitrophenol from paranitrophenylphosphate (pNPP) in cell lysates. pNPP $(20 \mathrm{mM})$ was added to each sample at $37^{\circ} \mathrm{C}$. After exactly 10 minutes, the reaction was stopped by adding $0.06 \mathrm{M} \mathrm{NaOH}$. Absorption was measured on the Wallac 1420 Victor2 plate reader at $405 \mathrm{~nm}$. For standards, ALP (10 U/ml) from bovine kidney (Sigma) was used.

\section{Mineralization}

To quantify the calcium content, cell lysates were incubated $48 \mathrm{~h}$ in $0.24 \mathrm{M} \mathrm{HCl}$ at $4{ }^{\circ} \mathrm{C}$. For analysis of calcium concentration in the culture medium, supernatant was collected from day 9 onwards. In both cases, calcium content was colorimetrically determined after addition of $1 \mathrm{M}$ ethanolamine buffer (pH 10.6), $19.8 \mathrm{mM} 8$ hydroxyquinoline and $0.35 \mathrm{mM} 0$-cresolphtalein complexone, at $595 \mathrm{~nm}$ on the Wallac 1420 Victor2.

For von Kossa staining, cell cultures were fixed for 15 minutes in $4 \%$ formaldehyde, stained by $5 \%$ silver nitrate solution (Sigma, 85228) for 30 minutes under a $60 \mathrm{~W}$ light and imaged using inverted microscope (Olympus CKX41, Zoeterwoude, NL).

\section{HUVEC Tube formation assay}

Growth factor-reduced matrigel (Corning, Tewksbury, MA, USA) was added to 96-wells plate and incubated at $37^{\circ} \mathrm{C}$ for 1 hour. HUVECs were resuspended in EBM medium supplemented with Nell-1, CCN2, HMGB1 or BMP2. EGM-2 complete medium was used as positive and EBM-2 medium as negative control. 15,000 cells were seeded on top of the matrigel, incubated at $37^{\circ} \mathrm{C}$ and imaged after 4,6 and 24 hours using inverted microscope. Three independent experiments in triplicate were performed. The results were analyzed using ImageJ software.

\section{Statistical analysis}

Data were analyzed with IBM Statistics 21 (SPSS). A linear mixed model was applied; the different conditions (different doses of the proteins studied) were considered a fixed parameter and the donors (experiments) as 
a random factor. A descriptive analysis was performed to assess the normal distribution of the data. When multiple comparisons were analyzed, Bonferroni test was performed. $\mathrm{P}<0.05$ was considered statistically significant.

\section{Results}

\section{Nell-1, CCN2 and HMGB1 stimulated MSC migration whereas BMP2 did not.}

To determine whether the proteins could recruit progenitor cells to the site of injury, we assessed their effects on migration of MSCs. The positive control PDGF-AB was chemoattractant showing a 4.6-fold increase compared to negative control (data not shown). Nell-1, CCN2, HMGB1, but not BMP2, were capable of inducing MSC migration (Figure 1). Nell-1 increased migration 2 fold, 2.3 fold and 2.79 fold compared to control in a dose dependent manner, albeit only statistically significant $(P<0.05)$ with the highest dose. CCN2 significantly increased migration at the lowest and medium dose (2.75-fold and 2.48-fold respectively), while the highest dose had no effect compared to control. In contrast, HMGB1 was chemotactic at the highest dose tested, $100 \mathrm{ng} / \mathrm{ml}$, with more than 5 -fold increase compared to control. Although there was a trend towards a stimulation of migration of BMP2 upon MSCs (1.3-1.6 fold increase), this effect was not significant.

\section{Nell-1, CCN2, HMGB1 and BMP2 proteins stimulated endothelial cell migration}

We explored the role of Nell-1, CCN2, HMGB1 and BMP2 on HUVEC recruitment. The positive control (EGM-2 complete medium) showed a 3.2-fold increase in migration compared to negative control (EBM medium). Interestingly, similar to MSCs Nell-1 and CCN2 stimulated HUVECs to migrate. Specifically, Nell-1 increased migration in a dose dependent manner, showing more than 2-fold increase with the highest dose, while CCN2 had a greater effect at the lowest dose (more than 2-fold increase compared to control). Although HMGB1 showed less pronounced effect upon HUVEC than MSC migration, it had a significant effect on migration in all the tested doses, showing a 2-fold increase compared to the control. It is noteworthy that, in contrast to the other three proteins which had similar effects on both cell types with regard to dose, BMP2 showed different effects, demonstrating a significantly higher endothelial cell migration at the lowest and medium dose supplied with more than 1.5-fold increase compared to control (Figure 2).

\section{BMP2 enhanced MSC osteogenic differentiation, Nell-1, CCN2 and HMGB1 had no effect}

Osteogenic differentiation of MSCs was assessed by calcium deposition. Supplementation with Nell-1, CCN2 or HMGB1 did not cause any increase or decrease in mineralization. However, when BMP2 was added, we observed a dose dependent stimulatory effect, with a significant increase in nodule formation at the highest 
dose provided (Figure 3A). The results were corroborated quantitatively by measuring the calcium content in the cell lysates, showing that addition of BMP2 at the highest dose provided (1000 ng/ml) had an almost 2fold increase in mineralization compared to the standard osteogenic differentiation media (Figure 3B).

\section{BMP2 inhibited pre-osteoblast differentiation and mineralization; Nell-1, CCN2 and HMGB1 had no effect}

The addition of Nell-1, CCN2 and HMGB1 didn't increase mineralization or ALP activity at either of the time points studied (Figure 4A). Interestingly, and in contrast to the effect observed with hMSCs, the addition of BMP2 to the pre-osteoblast culture had a direct inhibitory effect on differentiation and mineralization. The decrease in ALP activity became significant at day 16. In addition, a reduction in the ECM calcium content at the lowest dose provided was detected (Figure 4 A-B). However, when the highest dose was provided (1 $\mu \mathrm{g} / \mathrm{ml})$, the inhibitory effect was no longer observed and the mineralization reached control levels.

\section{Nell-1, CCN2, HMGB1 and BMP2 stimulated neovascularization}

We have determined the capability of the factors to promote formation of tubular like-structures by endothelial cells in vitro. There was a significant improvement in tube formation at the medium dose of Nell1 added $(100 \mathrm{ng} / \mathrm{ml})$, Furthermore, CCN2 and HMGB1 were able to enhance tube formation at the lowest doses supplied. BMP2 also enhanced tube formation in a dose dependent manner, resulting in a significant effect on tube formation when the highest dose was added (Figure 5B).

\section{Discussion}

We directly compared four proteins that are acknowledged for their apparent ability to stimulate osteogenesis in vitro or in vivo [20,31,46,47]. This is the first study to directly compare these proteins for their ability to induce recruitment, osteogenic differentiation and neovascularization using human cells. Our results demonstrate the ability of Nell-1, CCN2 and HMGB1 to attract both MSCs and endothelial cells even at low doses compared to BMP2. Since new blood vessel formation is crucial for bone development, we assessed neovascularization in an in vitro model, demonstrating that all four tested proteins were able to stimulate formation of tube-like structures. Interestingly, in contrast to BMP2, Nell-1, CCN2 and HMGB1 did not significantly increase the osteogenic differentiation capacity of MSCs above that induced by dexamethasone. Also of note, we observed that BMP2 negatively impacted pre-osteoblast mineralization, whereas the others had no effect.

\section{Effects on cell migration}


It is generally thought that BMPs are mediators of osteoprogenitor cell recruitment. However, it had been published that BMP2 had no effect in the recruitment of MSCs, neither in the cultured MSCs or in the marrow ablation tissues [48]. In our study we did not see any increase in MSC migration by BMP2 either. BMP2 chemotactic effect seems to vary between endothelial cell subtypes; studies performed with endothelial cells showed that BMP2 was not able to stimulate human aortic endothelial cell migration [6], but it stimulated HUVEC migration [49]. Our data confirmed that BMP2 is able to stimulate migration of HUVEC when doses between $10-100 \mathrm{ng} / \mathrm{ml}$ are supplied.

Where BMP2 had no effect on MSC migration and less than doubled the migration of HUVEC, we observed up to a 3-fold increase in MSC and HUVEC migration when HMGB1, CCN2 or Nell-1 were added to the culture. HMGB1, as a signal of tissue damage, is known to be capable of inducing migration in many different cell types including inflammatory cells $[36,50,51]$. Fewer papers exist investigating the effects of HMGB1 on osteogenic cells but those that do, indicate it to be important in cell recruitment. Meng et al., demonstrated that HMGB1 promotes MSCs migration up to 2.5-fold compared to control [38]. Our results confirm these findings, showing that HMGB1 has a highly significant chemotactic effect upon MSCs above doses of 50 $\mathrm{ng} / \mathrm{ml}$. To date, there is very little reported about HMGB1's chemotaxis upon primary endothelial cells. Low doses of HMGB1 are able to promote endothelial progenitor cell migration using transwells coated with fibronectin or fibrinogen [52]. Bauer et al. have performed a wound healing migration assay and have shown that $1 \mu \mathrm{g} / \mathrm{ml}$ of HMGB1 is able to induce migration on HUVEC [53]. We show that HMGB1 is highly chemoattractant to HUVECs, and even a hundred times lower concentration than $1 \mu \mathrm{g} / \mathrm{ml}$ is sufficient to induce more than 2-fold increase compared to control. In addition, from $10 \mathrm{ng} / \mathrm{ml}$ to $100 \mathrm{ng} / \mathrm{ml}$ we observed a similar chemoattractant effect, suggesting a low dose is sufficient to stimulate endothelial cell migration.

CCN2 has been shown to promote migration of human MSCs and human dermal microvascular endothelial cells when transfected with pCCN2 $[24,25]$. Nonetheless, the effect of the addition of the protein CCN2 to MSCs or endothelial cells had not been studied before. We demonstrated that the addition of low dose (10 $\mathrm{ng} / \mathrm{ml}=0.89 \mathrm{nM}$ ) of CCN2 to the media is sufficient to obtain a significant migratory response from MSCs and HUVECS, reaching more than a 4-fold increase compared to the control. The fact that CCN2 showed an inverse dose response is potentially interesting for endogenous cell recruitment though slow release systems.

Nell-1 has been shown to inhibit renal carcinoma cell (RCC) migration and adhesion [54]. However, we did not find published data about the effect of Nell-1 upon MSC and EC migration. We demonstrated in this study its ability to promote migration of both cell types. In fact, it was able to promote endothelial cell migration at lower doses than BMP2 (BMP2, $100 \mathrm{ng} / \mathrm{ml}=3.8 \mathrm{nM}$; Nell-1, $100 \mathrm{ng} / \mathrm{ml}=0.7 \mathrm{nM})$ and MSC migration when BMP2 didn't.

\section{Effects on osteogenesis}


BMP2 is the best known osteogenic factor. Next to the capacity to induce bone formation in vivo, the capacity of BMP2 to induce osteogenic differentiation of MSCs in vitro has already been tested [55, 56]. Our data confirm this as we observed almost 2-fold increase when $1 \mu \mathrm{g} / \mathrm{ml}$ of BMP2 was added to the culture. However, little is known about its effect on osteoblasts. Here we observed an inhibition of mineralization when BMP2 was added to osteoblast cultures in a concentration range of $10-100 \mathrm{ng} / \mathrm{ml}$. Interestingly, we did not observe that inhibitory effect when the highest dose was added $(1 \mu \mathrm{g} / \mathrm{ml})$. This could be due to the fact that SV-HFOs express activin [57] which may interfere with BMP2 or simply because BMP2 is not an essential stimulus when the cells are already committed to the osteogenic pathway. Many studies indicated HMGB1's role in the induction of endochondral ossification in vivo and that it may act as a bone resorption signal [31]. However, HMGB1 has not been used as therapeutic agent for bone regeneration and whether it has any effect on either osteoprogenitor or osteoblasts differentiation and mineralization is barely studied. We did not observe any effect on osteogenic differentiation when HMGB1 was added to the MSC or pre-osteoblast culture media. Although it has been shown that CCN2 expression is increased in mesenchymal stem cells and osteoblasts during bone formation [20], the effect of the addition of the protein CCN2 to MSCs or to osteoblasts had not been examined previously. Our study demonstrates that while it promotes migration of osteoprogenitor cells, CCN2 is not able to increase osteogenesis in contrast to a published study by Safadi, Xu [58], who used rat primary osteoblasts and showed an increase on calcium deposition when $100 \mathrm{ng} / \mathrm{ml}$ of CCN2 was added to the culture beginning at day 11 . We cannot exclude that the differences in experimental setup, including addition of dexamethasone and single dosing of CCN2, might explain the results.

With regard to Nell-1, most of the osteogenic differentiation studies have been performed with either human osteosarcoma cell lines or murine osteoblast-like cells [59-61]. These studies have shown that, when transfected with Nell-1, these cells increase late osteogenic differentiation markers and ECM mineralization. Recently, Pang et al have identified a functional transcript of Nell-1 able to induce osteogenic differentiation of a murine MSC cell line [62]. However, no information on human MSCs or osteoblasts was available. We observed an osteogenic trend when Nell-1 was added at low doses to pre-osteoblasts, albeit with high variability between cultures. Even then, comparison on a molar basis suggests that Nell-1 could have an osteogenic inducing effect even at low doses, in contrast to BMP2 that exhibited the reverse effect. Although we did not observe a significant effect of Nell-1 on osteogenic differentiation, a synergistic effect of Nell-1 and BMP2 has been shown on osteogenesis in vitro [63]. Moreover, Nell-1 can suppress BMP2-induced inflammation and enhance BMP-2 induced bone formation in vivo [64-66]. Therefore, Nell-1 is a potentially interesting candidate to be used alone or with BMP2. Nell-1 and BMP2 might stimulate different stages of osteogenic differentiation; where Nell-1 stimulates osteoprogenitor cell migration and could enhance preosteoblast differentiation, BMP2 might promote differentiation of skeletal stem cells.

\section{Effects on vascularization}

BMP2 had been shown to stimulate angiogenesis in developing tumors $[6,67]$. In bone tissue engineering, however, BMP2 is frequently used in combination with angiogenic factors as VEGF or angiopoietin 1 [68-70], 
suggesting BMP2 does not optimally induce vascularization. Here we demonstrated the ability of BMP2 to induce the formation of tube-like structures at a dose of $1 \mu \mathrm{g} / \mathrm{ml}$, a relatively much higher dose than required for CCN2, HMGB1 or Nell-1. HMGB-1 is known to have diverse roles in angiogenesis during disease and tissue repair [42] and has been suggested to induce angiogenesis through a VEGF-dependent mechanism [71]. HMGB1 was shown to induce tube formation by microvascular endothelial cells at doses ranging from 0.1-1 $\mu \mathrm{g} / \mathrm{ml}[72,73]$. Here we show that much lower doses of HMGB1 are sufficient to recruit endothelial cells and to promote tube formation. CCN2 has been shown to act as a pro-angiogenic factor, coordinating vasculature formation during skeletal development $[21,74]$ but also as anti-angiogenic agent inhibiting VEGF-induced angiogenesis [29], suggesting that CCN2 regulates angiogenesis through direct and indirect mechanisms [75]. We show that CCN2 has pro-angiogenic properties when it is added directly to endothelial cells, even at much lower doses than are required for BMP2 to induce a similar effect. Therefore, CCN2 might also be an interesting factor to be combined in future studies with a powerful osteoinductive growth factor, due to its chemotactic and angiogenic features. Although some studies have shown that Nell-1 induces VEGF expression in human pericytes and perivascular stem cells [12, 76], to our knowledge, there are no previous publications investigating the effects of Nell-1 on vascularization of endothelial cells. We demonstrate that the addition of Nell-1 positively affects endothelial cell migration within a tight dose range, producing a significant increase at $100 \mathrm{ng} / \mathrm{ml}$, a larger dose than needed with either HMGB1 or CCN2, but still 10 times lower than needed with BMP2.

\section{Bone defect repair}

To accelerate and optimize bone remodeling, using more than one type of growth factor involved in bone formation could be preferable to reduce possible side-effects due to high doses used when single factor therapies are applied. In addition, several studies have shown that, not only the dose but also the timing of release of the proteins from the carrier used for bone formation greatly modifies the outcome [77]. Based on the promising properties of Nell-1, HMGB1, CCN2 and BMP2 with regard to their promotion of bone formation related processes, in vivo analyses using dual release systems should be performed to assess their potency for bone defect repair.

\section{Acknowledgements}

The authors would like to thanks Dr. Joachim Nickel for his generous gift of BMP2. The research leading to these results has received funding from the European Union Seventh Framework Programme FP7-PEOPLE2013-ITN under grant agreement $n^{\circ} 607051$. 
1. Giannoudis, P.V., H. Dinopoulos, and E. Tsiridis, Bone substitutes: an update. Injury, 2005. 36 Suppl 3: p. S20-7.

2. Finkemeier, C.G., Bone-grafting and bone-graft substitutes. J Bone Joint Surg Am, 2002. 84A(3): p. 454-64.

3. Brydone, A.S., D. Meek, and S. Maclaine, Bone grafting, orthopaedic biomaterials, and the clinical need for bone engineering. Proc Inst Mech Eng H, 2010. 224(12): p. 1329-43.

4. Hustedt, J.W. and D.J. Blizzard, The controversy surrounding bone morphogenetic proteins in the spine: a review of current research. Yale J Biol Med, 2014. 87(4): p. 549-61.

5. Carreira, A.C., et al., Bone morphogenetic proteins: facts, challenges, and future perspectives. J Dent Res, 2014. 93(4): p. 335-45.

6. Langenfeld, E.M. and J. Langenfeld, Bone morphogenetic protein-2 stimulates angiogenesis in developing tumors. Mol Cancer Res, 2004. 2(3): p. 141-9.

7. Zara, J.N., et al., High doses of bone morphogenetic protein 2 induce structurally abnormal bone and inflammation in vivo. Tissue Eng Part A, 2011. 17(9-10): p. 1389-99.

8. Carragee, E.J., et al., Cancer risk after use of recombinant bone morphogenetic protein-2 for spinal arthrodesis. J Bone Joint Surg Am, 2013. 95(17): p. 1537-45.

9. Blonder, J., Z. Xiao, and T.D. Veenstra, Proteomic profiling of differentiating osteoblasts. Expert Rev Proteomics, 2006. 3(5): p. 483-96.

10. Ting, K., et al., Human NELL-1 expressed in unilateral coronal synostosis. J Bone Miner Res, 1999. 14(1): p. 80-9.

11. Aghaloo, T., et al., Nell-1-induced bone regeneration in calvarial defects. Am J Pathol, 2006. 169(3): p. 903-15.

12. Zhang, X., et al., The Nell-1 growth factor stimulates bone formation by purified human perivascular cells. Tissue Eng Part A, 2011. 17(19-20): p. 2497-509.

13. Yuan, W., et al., NELL-1 based demineralized bone graft promotes rat spine fusion as compared to commercially available BMP-2 product. J Orthop Sci, 2013. 18(4): p. 646-57.

14. James, A.W., et al., Vertebral Implantation of NELL-1 Enhances Bone Formation in an Osteoporotic Sheep Model. Tissue Eng Part A, 2016. 22(11-12): p. 840-9.

15. James, A.W., et al., NELL-1 in the treatment of osteoporotic bone loss. Nat Commun, 2015. 6: p. 7362.

16. Cowan, C.M., et al., NELL-1 increases pre-osteoblast mineralization using both phosphate transporter Pit1 and Pit2. Biochem Biophys Res Commun, 2012. 422(3): p. 351-7. 
17. Turner, N.J., et al., Human NELL1 protein augments constructive tissue remodeling with biologic scaffolds. Cells Tissues Organs, 2013. 198(4): p. 249-65.

18. Kikuchi, T., et al., Promotion of bone regeneration by CCN2 incorporated into gelatin hydrogel. Tissue Eng Part A, 2008. 14(6): p. 1089-98.

19. Abd El Kader, T., et al., The regenerative effects of CCN2 independent modules on chondrocytes in vitro and osteoarthritis models in vivo. Bone, 2014. 59: p. 180-8.

20. Arnott, J.A., et al., The role of connective tissue growth factor (CTGF/CCN2) in skeletogenesis. Crit Rev Eukaryot Gene Expr, 2011. 21(1): p. 43-69.

21. Ivkovic, S., et al., Connective tissue growth factor coordinates chondrogenesis and angiogenesis during skeletal development. Development, 2003. 130(12): p. 2779-91.

22. Hendesi, H., et al., Integrin mediated adhesion of osteoblasts to connective tissue growth factor (CTGF/CCN2) induces cytoskeleton reorganization and cell differentiation. PLoS One, 2015. 10(2): p. e0115325.

23. Kubota, S. and M. Takigawa, The role of CCN2 in cartilage and bone development. J Cell Commun Signal, 2011. 5(3): p. 209-17.

24. Markiewicz, M., et al., Connective tissue growth factor (CTGF/CCN2) mediates angiogenic effect of S1P in human dermal microvascular endothelial cells. Microcirculation, 2011. 18(1): p. 1-11.

25. Wang, J.J., et al., Osteogenic differentiation of mesenchymal stem cells promoted by overexpression of connective tissue growth factor. J Zhejiang Univ Sci B, 2009. 10(5): p. 355-67.

26. Hall-Glenn, F., et al., CCN2/connective tissue growth factor is essential for pericyte adhesion and endothelial basement membrane formation during angiogenesis. PLoS One, 2012. 7(2): p. e30562.

27. Takigawa, M., CCN2: a master regulator of the genesis of bone and cartilage. J Cell Commun Signal, 2013. 7(3): p. 191-201.

28. Lau, L.F. and S.C. Lam, The CCN family of angiogenic regulators: the integrin connection. Exp Cell Res, 1999. 248(1): p. 44-57.

29. Inoki, l., et al., Connective tissue growth factor binds vascular endothelial growth factor (VEGF) and inhibits VEGF-induced angiogenesis. FASEB J, 2002. 16(2): p. 219-21.

30. Hashimoto, G., et al., Matrix metalloproteinases cleave connective tissue growth factor and reactivate angiogenic activity of vascular endothelial growth factor 165. J Biol Chem, 2002. 277(39): p. 36288-95.

31. Yang, J., et al., HMGB1 is a bone-active cytokine. J Cell Physiol, 2008. 214(3): p. 730-9. 
35. Riuzzi, F., G. Sorci, and R. Donato, The amphoterin (HMGB1)/receptor for advanced glycation end products (RAGE) pair modulates myoblast proliferation, apoptosis, adhesiveness, migration, and invasiveness. Functional inactivation of RAGE in L6 myoblasts results in tumor formation in vivo. J Biol Chem, 2006. 281(12): p. 8242-53.

6. Rouhiainen, A., et al., Regulation of monocyte migration by amphoterin (HMGB1). Blood, 2004. 104(4): p. 1174-82.

37. Martinotti, S., et al., HMGB1 Osteo-Modulatory Action on Osteosarcoma SaOS-2 Cell Line: An Integrated Study From Biochemical and -Omics Approaches. J Cell Biochem, 2016. 117(11): p. 2559-69.

38. Meng, E., et al., High mobility group box 1 protein inhibits the proliferation of human mesenchymal stem cells and promotes their migration and differentiation along osteoblastic pathway. Stem Cells Dev, 2008. 17(4): p. 805-13.

39. Li, M., et al., rhHMGB1 drives osteoblast migration in a TLR2/TLR4- and NF-kappaBdependent manner. Biosci Rep, 2016.

40. Feng, L., et al., HMGB1 promotes the secretion of multiple cytokines and potentiates the osteogenic differentiation of mesenchymal stem cells through the Ras/MAPK signaling pathway. Exp Ther Med, 2016. 12(6): p. 3941-3947.

41. Yu, Y., et al., HMGB1 is a therapeutic target for leukemia. Am J Blood Res, 2012. 2(1): p. 3643.

42. Yang, S., et al., High-mobility group box-1 and its role in angiogenesis. J Leukoc Biol, 2014. 95(4): p. 563-74.

43. Chiba, H., et al., Establishment and characterization of a simian virus 40-immortalized osteoblastic cell line from normal human bone. Jpn J Cancer Res, 1993. 84(3): p. 290-7.

44. van Driel, M., et al., Evidence that both 1alpha,25-dihydroxyvitamin D3 and 24hydroxylated D3 enhance human osteoblast differentiation and mineralization. J Cell Biochem, 2006. 99(3): p. 922-35.

45. Lowry, O.H., et al., The quantitative histochemistry of brain. II. Enzyme measurements. J Biol Chem, 1954. 207(1): p. 19-37. 
46. Zhang, X., et al., The role of NELL-1, a growth factor associated with craniosynostosis, in promoting bone regeneration. J Dent Res, 2010. 89(9): p. 865-78.

47. Gugala, Z., et al., Adenovirus BMP2-induced osteogenesis in combination with collagen carriers. Biomaterials, 2007. 28(30): p. 4469-79.

48. Bais, M.V., et al., BMP2 is essential for post natal osteogenesis but not for recruitment of osteogenic stem cells. Bone, 2009. 45(2): p. 254-66.

49. Finkenzeller, G., S. Hager, and G.B. Stark, Effects of bone morphogenetic protein 2 on human umbilical vein endothelial cells. Microvasc Res, 2012. 84(1): p. 81-5.

50. Scaffidi, P., T. Misteli, and M.E. Bianchi, Release of chromatin protein HMGB1 by necrotic cells triggers inflammation. Nature, 2002. 418(6894): p. 191-5.

51. Yang, H., et al., The many faces of HMGB1: molecular structure-functional activity in inflammation, apoptosis, and chemotaxis. J Leukoc Biol, 2013. 93(6): p. 865-73.

52. Chavakis, E., et al., High-mobility group box 1 activates integrin-dependent homing of endothelial progenitor cells. Circ Res, 2007. 100(2): p. 204-12.

53. Bauer, E.M., et al., High mobility group Box 1 inhibits human pulmonary artery endothelial cell migration via a Toll-like receptor 4-and interferon response factor 3-dependent mechanism(s). J Biol Chem, 2013. 288(2): p. 1365-73.

54. Nakamura, R., et al., Expression and regulatory effects on cancer cell behavior of NELL1 and NELL2 in human renal cell carcinoma. Cancer Sci, 2015. 106(5): p. 656-64.

55. Rickard, D.J., et al., Induction of rapid osteoblast differentiation in rat bone marrow stromal cell cultures by dexamethasone and BMP-2. Dev Biol, 1994. 161(1): p. 218-28.

56. Edgar, C.M., et al., Autogenous regulation of a network of bone morphogenetic proteins (BMPs) mediates the osteogenic differentiation in murine marrow stromal cells. Bone, 2007. 40(5): p. 1389-98.

57. Woeckel, V.J., et al., 1alpha,25-dihydroxyvitamin D3 stimulates activin A production to finetune osteoblast-induced mineralization. J Cell Physiol, 2013. 228(11): p. 2167-74.

58. Safadi, F.F., et al., Expression of connective tissue growth factor in bone: its role in osteoblast proliferation and differentiation in vitro and bone formation in vivo. J Cell Physiol, 2003. 196(1): p. 51-62.

59. Zhang, X., et al., Craniosynostosis in transgenic mice overexpressing Nell-1. J Clin Invest, 2002. 110(6): p. 861-70.

60. Bokui, N., et al., Involvement of MAPK signaling molecules and Runx2 in the NELL1-induced osteoblastic differentiation. FEBS Lett, 2008. 582(2): p. 365-71. 
65. Shen, J., et al., Novel Wnt Regulator NEL-Like Molecule-1 Antagonizes Adipogenesis and

61. Zou, X., et al., NELL-1 binds to APR3 affecting human osteoblast proliferation and differentiation. FEBS Lett, 2011. 585(15): p. 2410-8.

62. Pang, S., et al., Proliferation and Osteogenic Differentiation of Mesenchymal Stem Cells Induced by a Short Isoform of NELL-1. Stem Cells, 2015. 33(3): p. 904-15.

63. Cowan, C.M., et al., Synergistic effects of Nell-1 and BMP-2 on the osteogenic differentiation of myoblasts. J Bone Miner Res, 2007. 22(6): p. 918-30.

64. Shen, J., et al., BMP2-induced inflammation can be suppressed by the osteoinductive growth factor NELL-1. Tissue Eng Part A, 2013. 19(21-22): p. 2390-401. Augments Osteogenesis Induced by Bone Morphogenetic Protein 2. Am J Pathol, 2016. 186(2): p. 419-34.

66. Zhu, S., et al., Combined effects of recombinant human BMP-2 and Nell-1 on bone regeneration in rapid distraction osteogenesis of rabbit tibia. Injury, 2011. 42(12): p. 146773.

67. Raida, M., et al., Bone morphogenetic protein 2 (BMP-2) and induction of tumor angiogenesis. J Cancer Res Clin Oncol, 2005. 131(11): p. 741-50.

68. Kempen, D.H., et al., Effect of local sequential VEGF and BMP-2 delivery on ectopic and orthotopic bone regeneration. Biomaterials, 2009. 30(14): p. 2816-25.

69. Choi, H., et al., The Angiopoietin-1 Variant COMP-Ang1 Enhances BMP2-Induced Bone Regeneration with Recruiting Pericytes in Critical Sized Calvarial Defects. PLoS One, 2015. 10(10): p. e0140502.

70. Patel, Z.S., et al., Dual delivery of an angiogenic and an osteogenic growth factor for bone regeneration in a critical size defect model. Bone, 2008. 43(5): p. 931-40.

71. Biscetti, F., et al., High-mobility group box-1 protein promotes angiogenesis after peripheral ischemia in diabetic mice through a VEGF-dependent mechanism. Diabetes, 2010. 59(6): p. 1496-505.

72. Kim, H.Y., et al., Inhibition of HMGB1-induced angiogenesis by cilostazol via SIRT1 activation in synovial fibroblasts from rheumatoid arthritis. PLoS One, 2014. 9(8): p. e104743.

73. Sachdev, U., et al., High mobility group box 1 promotes endothelial cell angiogenic behavior in vitro and improves muscle perfusion in vivo in response to ischemic injury. J Vasc Surg, 2012. 55(1): p. 180-91. 
74. Shimo, T., et al., Connective tissue growth factor induces the proliferation, migration, and tube formation of vascular endothelial cells in vitro, and angiogenesis in vivo. J Biochem, 1999. 126(1): p. 137-45.

75. Brigstock, D.R., Regulation of angiogenesis and endothelial cell function by connective tissue growth factor (CTGF) and cysteine-rich 61 (CYR61). Angiogenesis, 2002. 5(3): p. 15365.

76. Askarinam, A., et al., Human perivascular stem cells show enhanced osteogenesis and vasculogenesis with Nel-like molecule I protein. Tissue Eng Part A, 2013. 19(11-12): p. 138697.

77. Kim, Y.H. and Y. Tabata, Dual-controlled release system of drugs for bone regeneration. Adv Drug Deliv Rev, 2015. 
Page 17 of 24

훙

$\stackrel{a}{\Xi}$

$\widehat{\widehat{F}}$

Nell-1
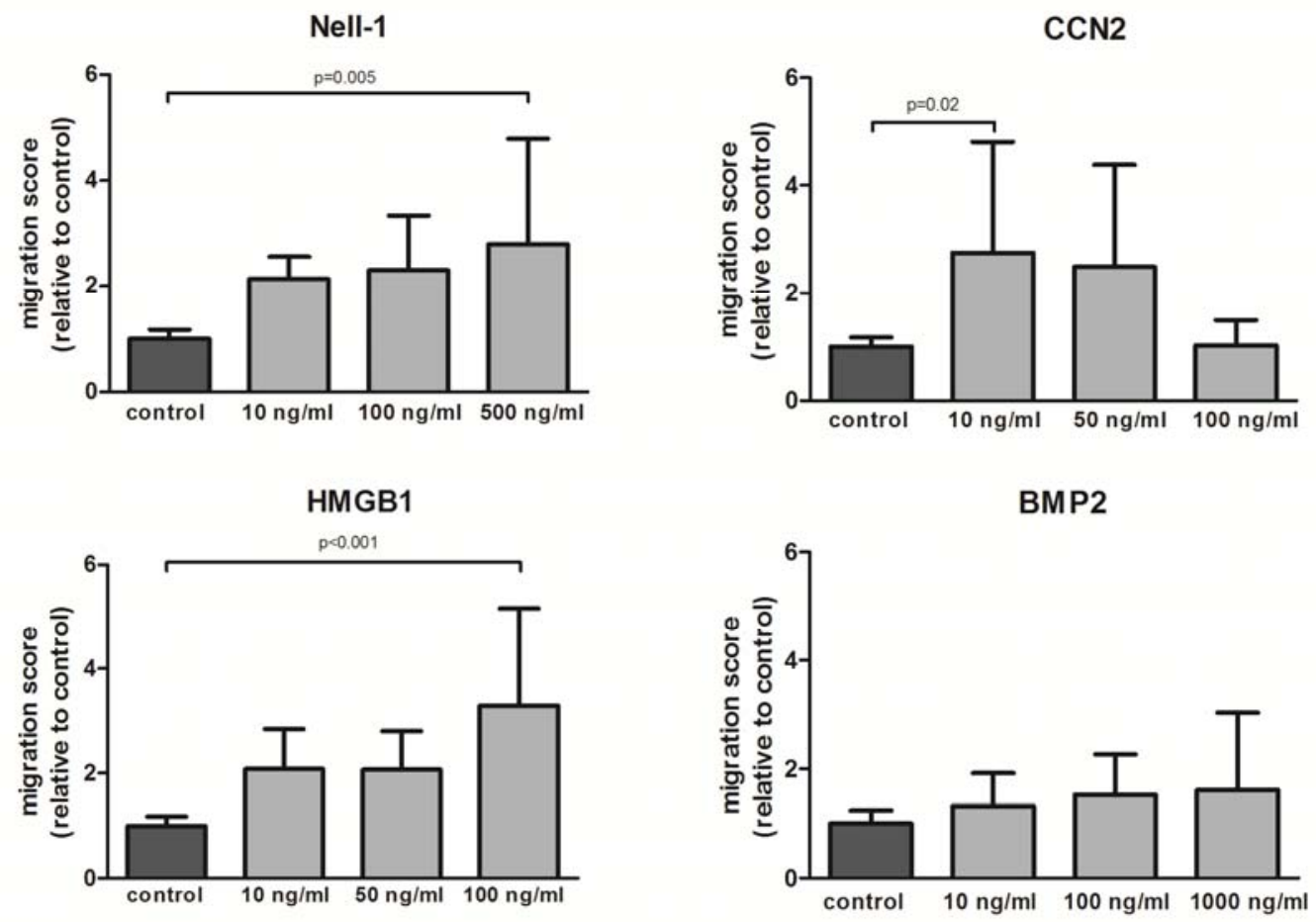

Figure 1. Nell-1, CCN2 and HMGB1 stimulated MSC migration. Average migration of MSCS

exposed to several doses of each factor relative to the negative control ( $n=4$ donors in duplicate).

The bars represent the mean \pm SD. 
بேं

Nell-1

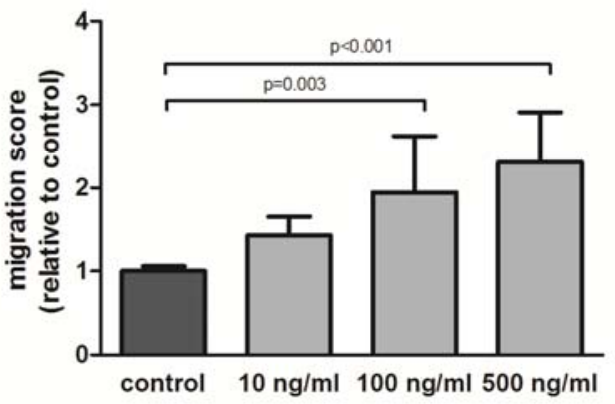

HMGB1

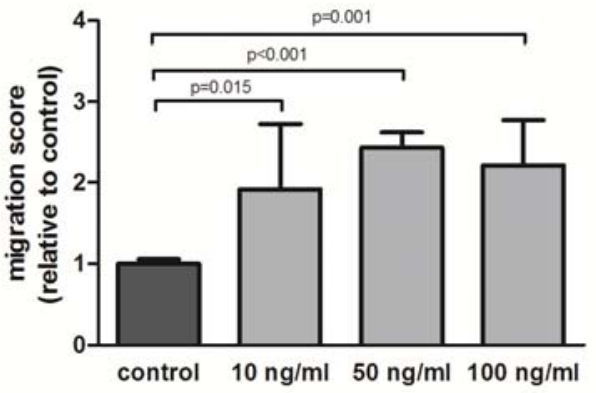

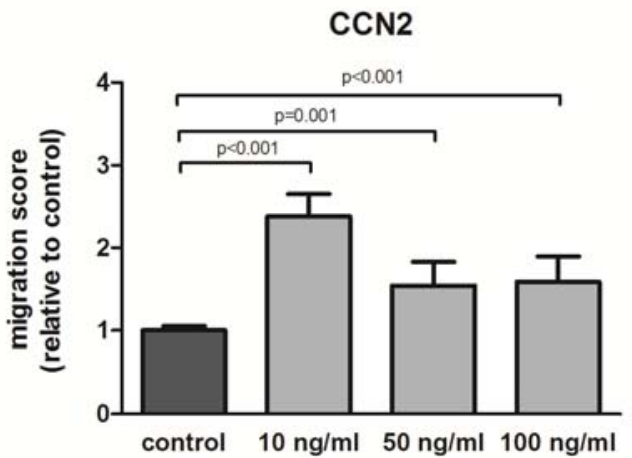

BMP2

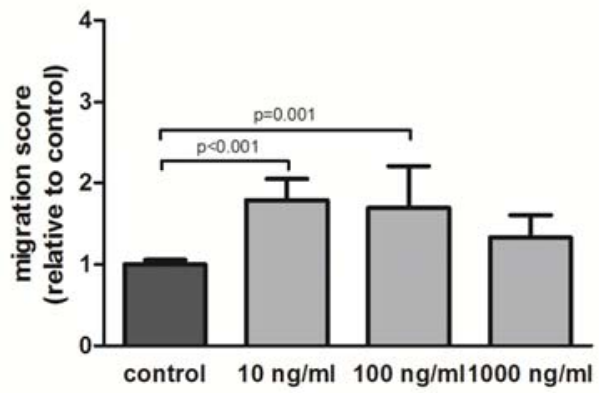

Figure 2. Nell-1, CCN2, HMGB1 and BMP2 stimulated endothelial cell migration. Average

migration of HUVECs exposed to several doses of each factor relative to the negative control $(n=3$

donors in duplicate). The bars represent the mean \pm SD. 
Page 19 of 24

กิ

己.

正

ํㅛㅁ

象

ㅇํㄹ

过忐

ฮิ่. ำ

कิष

으물굴

후을

ㄲีํี

$\sum_{0}$

을

링ंड

ㅊ.ㅁำ

ํㅡㄹㅈㅡ

ํํㅇㅇㅡ

.릉

클들

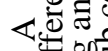

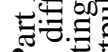

A
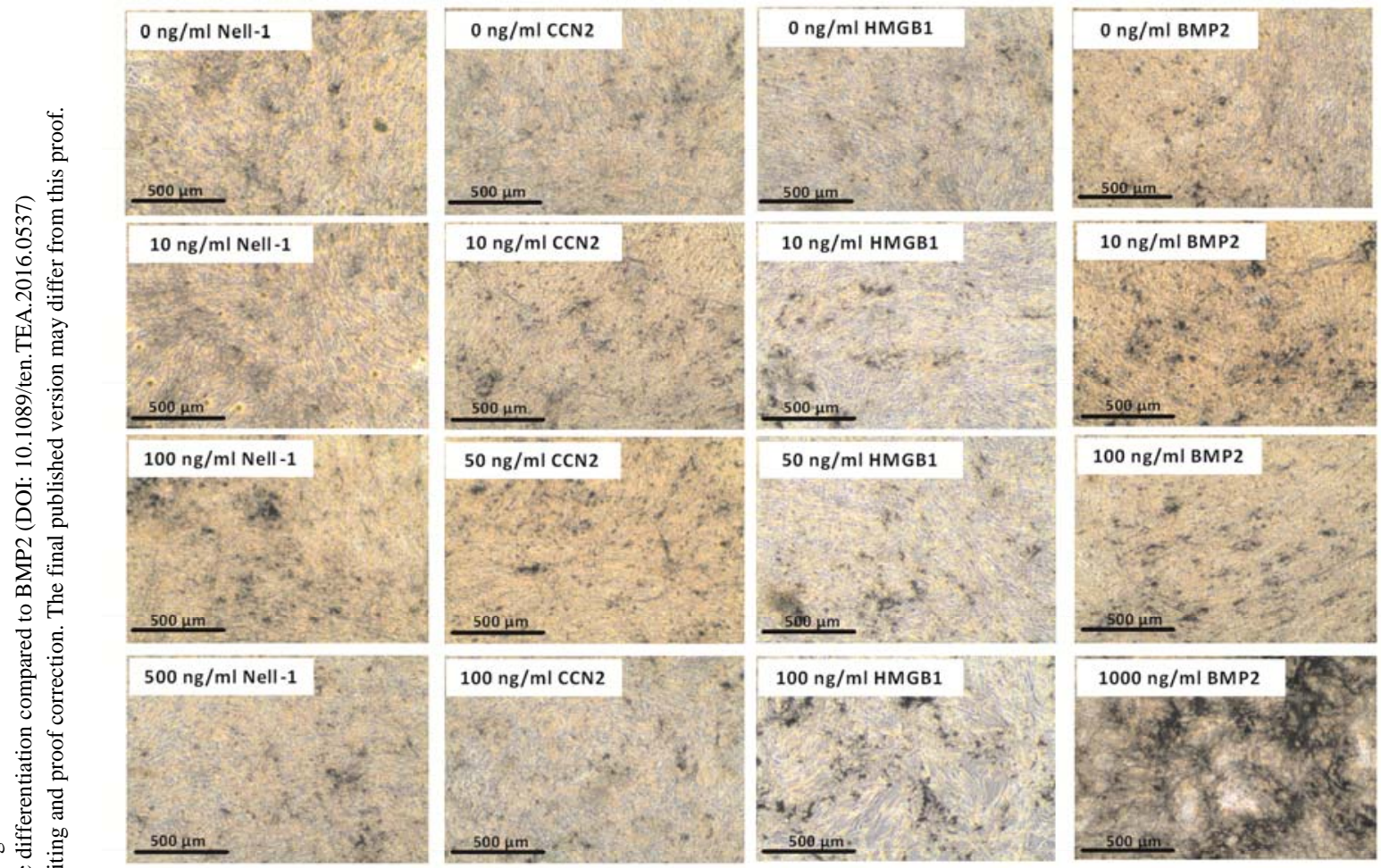

$B$

Nell-1
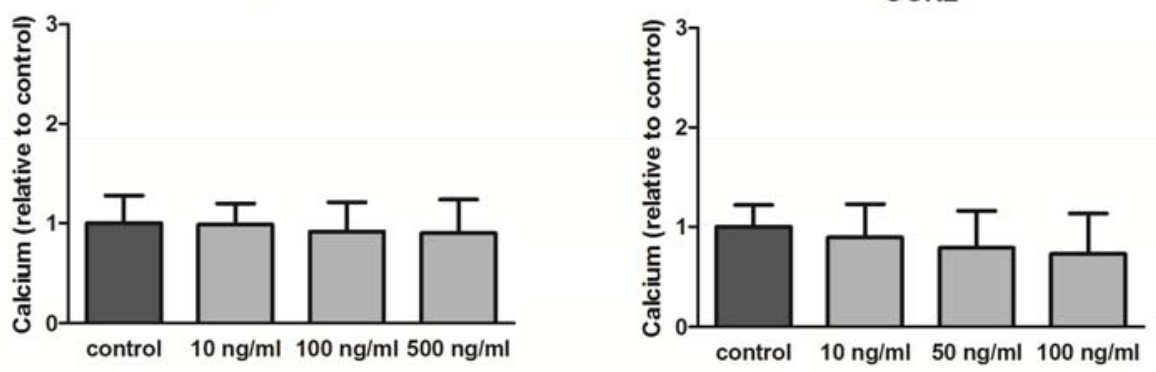

HMGB1
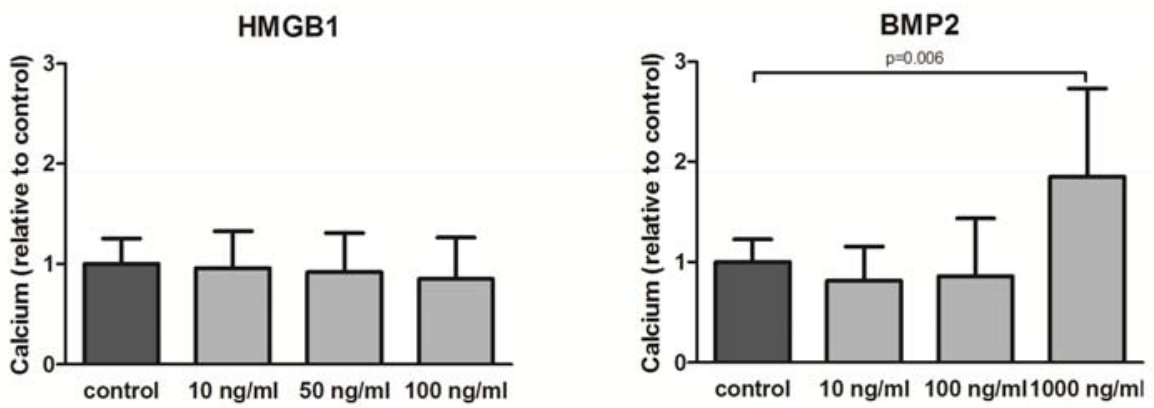
Figure 3. Effect of Nell-1, CCN2, HMGB1 and BMP2 on the MSC mineralization. Human MSCs were induced to mineralize in the absence or continuous presence of Nell-1, CCN2, HMGB1 or BMP2. A. Von Kossa staining of nodule formation at the onset of mineralization. Pictures were पேं 
Page 21 of 24

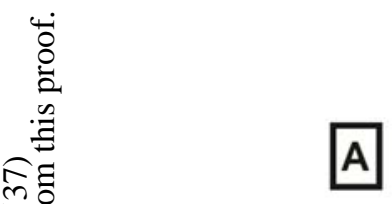

ใด

离离

떱 롤

छี.

केष

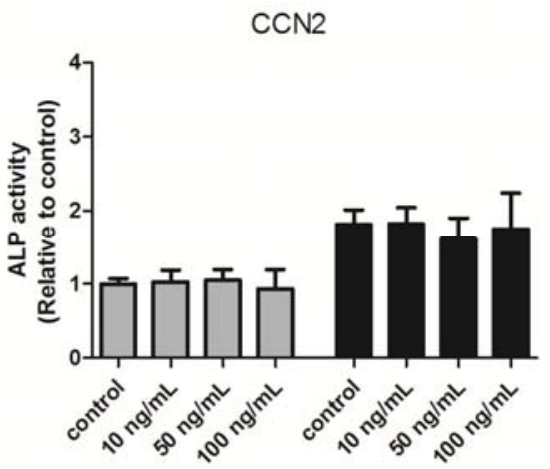

HMGB1
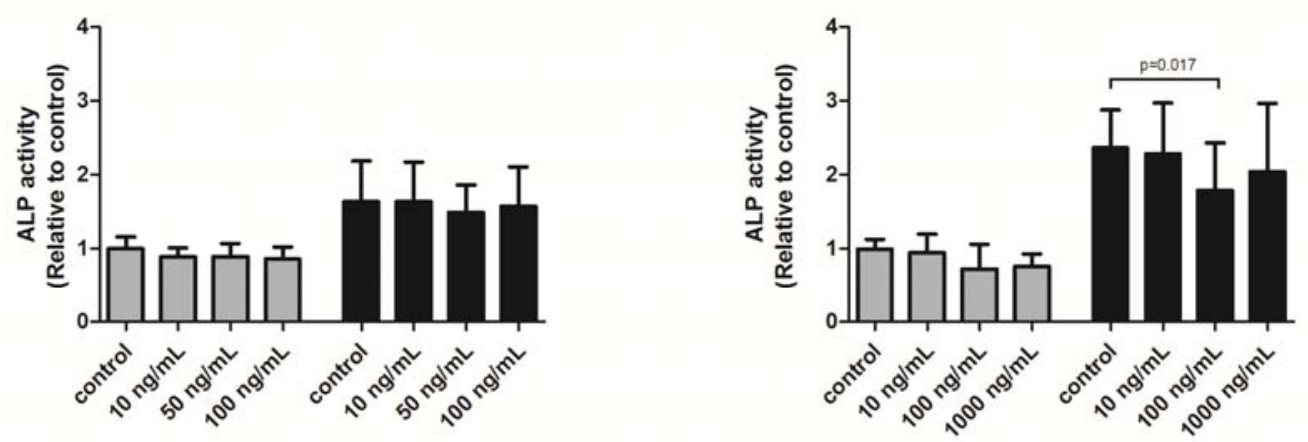

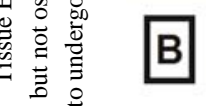
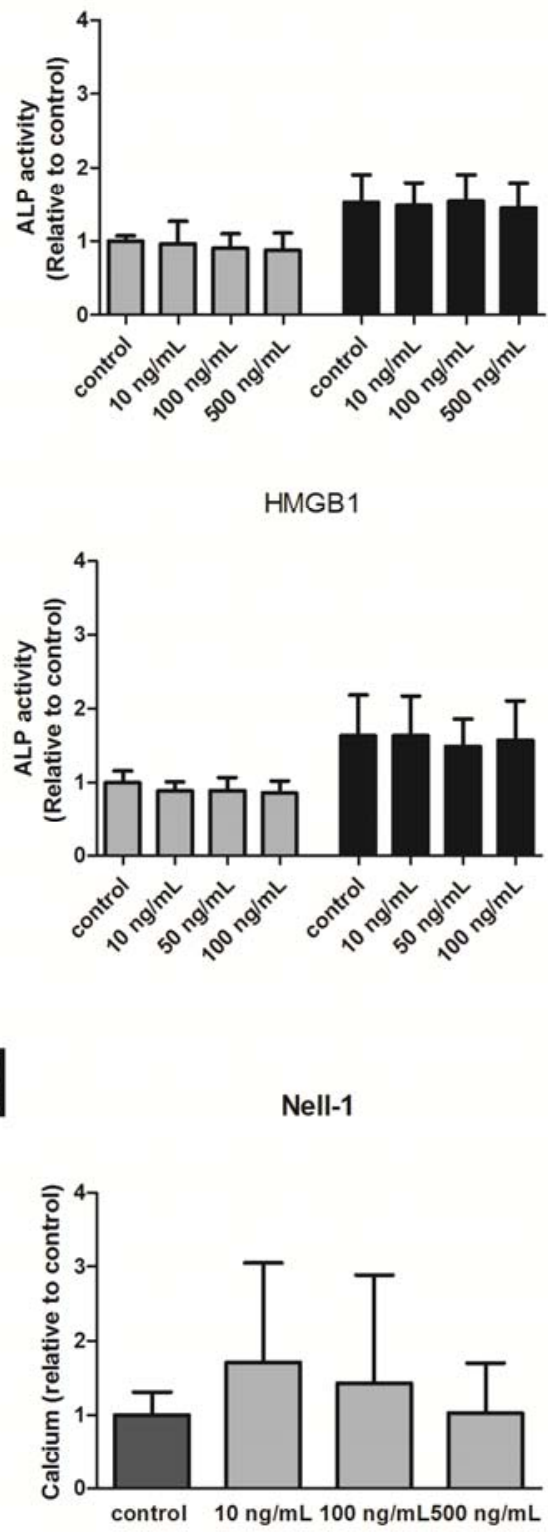

HMGB1
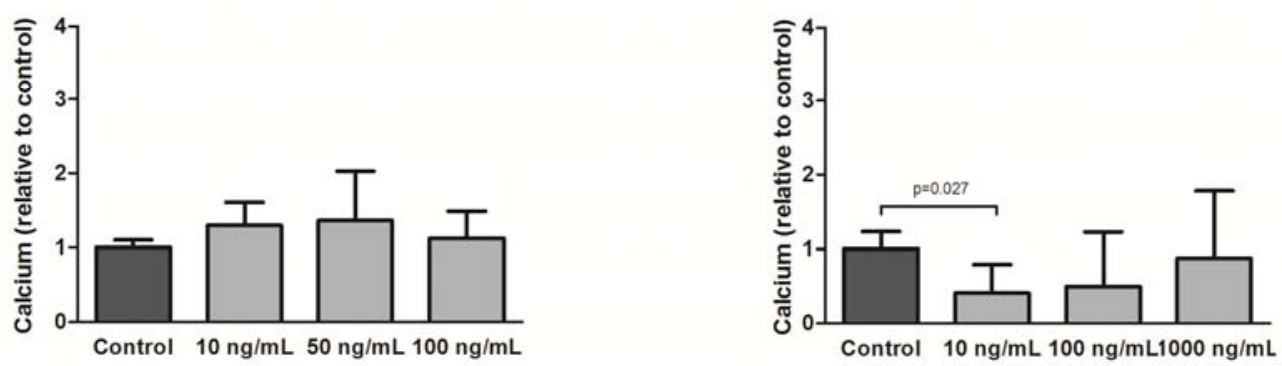
Figure 4. Effect of Nell-1, CCN, HMGB1 and BMP-2 on the osteoblast differentiation measured by

ALP activity and mineralization. A. Alkaline phosphatase (ALP) activity $\left(\mathrm{mU} / \mathrm{cm}^{2}\right)$ during SV-HFO

culture in osteogenic differentiation medium (control) and after continuous addition of the tested

proteins at day 9 (grey bars) and 16 (black bars) of culture. Results are shown relative to day 9

control. B. Quantification of calcium deposition $\left(\mathrm{nmol} / \mathrm{cm}^{2}\right)$ in the extracellular matrix at day 16.

Values are expressed as fold change compared to osteogenic medium without additional proteins.

Results are shown relative to control in both graphs ( $n=3$ experiments performed in triplicate). The bars show the mean \pm SD. 
Page 23 of 24

กิ

을

A
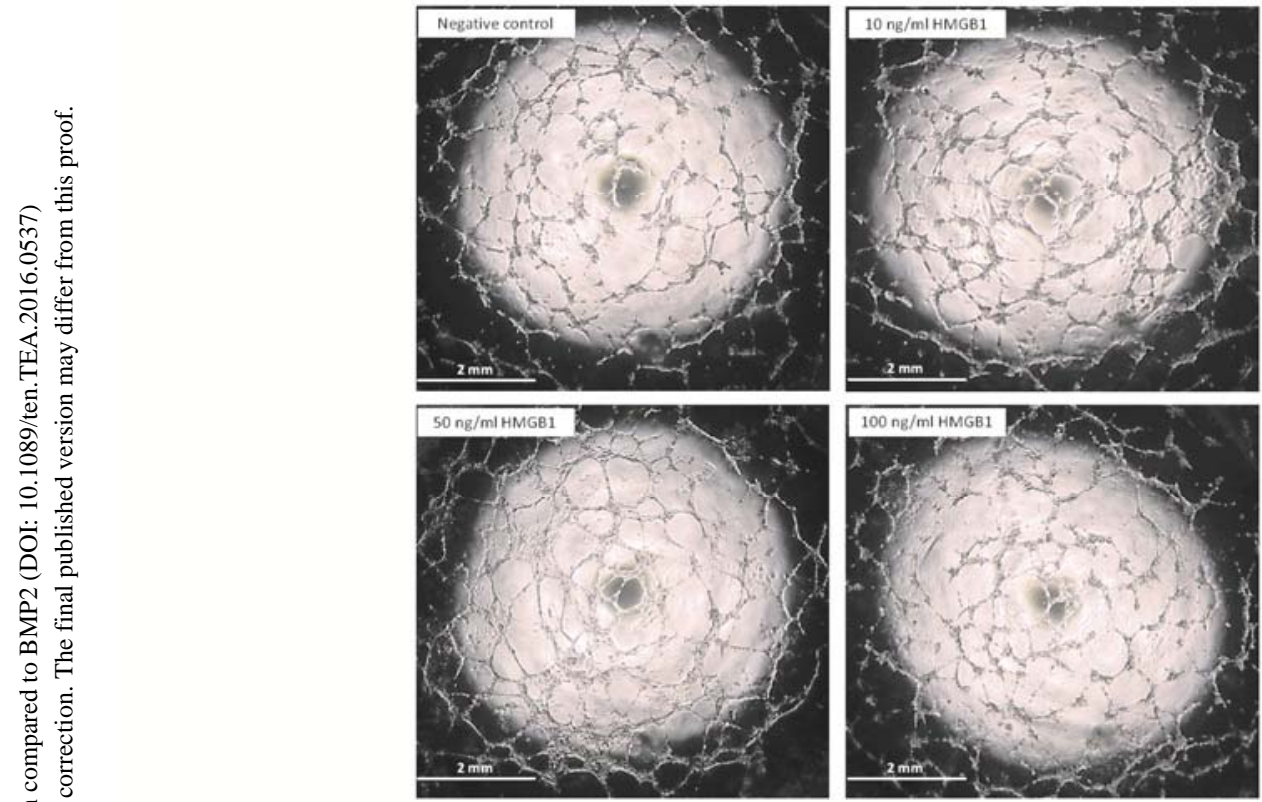

B

Nell1

CCN2
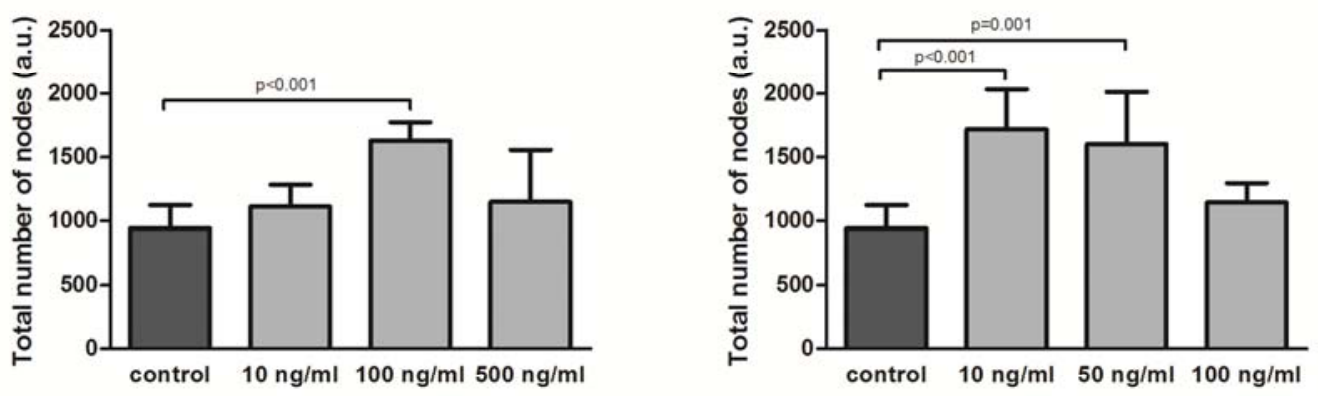

HMGB1

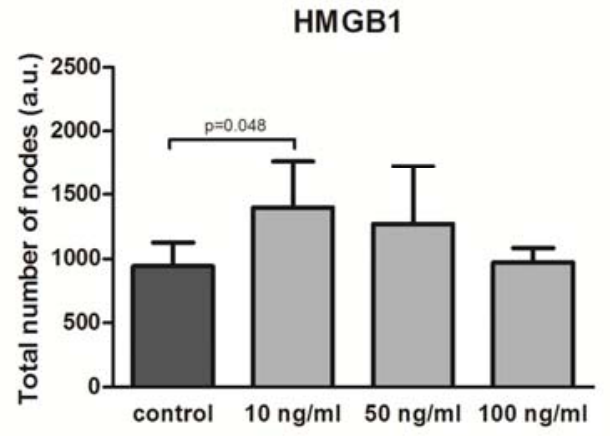

BMP2

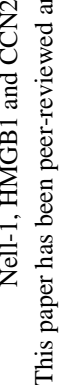

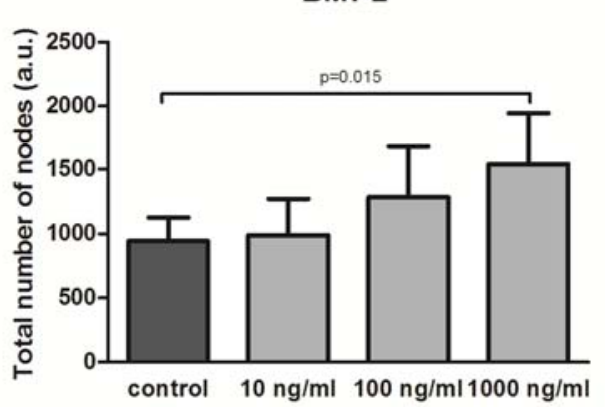

Figure 5. Effect of Nell-1, CCN2, HMGB1 and BMP2 HUVEC on tube formation on matrigel. 
A. Representative picture of tube-like structures formed by HUVEC after $6 \mathrm{~h}$ treatment with vehicle control, $10 \mathrm{ng} / \mathrm{ml}$ HMGB1, $50 \mathrm{ng} / \mathrm{ml} \mathrm{HMGB} 1$ and $100 \mathrm{ng} / \mathrm{ml} \mathrm{HMGB1}$. Pictures were taken The bars show the mean with SD. 